\title{
Evolution of bed load grain size distribution with increasing flow strength and the effect of flow duration on the caliber of bed load sediment yield in ephemeral gravel bed rivers
}

\author{
D. Mark Powell \\ Department of Geography, Leicester University, Leicester, England, United Kingdom
}

Ian Reid

Department of Geography, Loughborough University, Loughborough, England, United Kingdom

Jonathan B. Laronne

Department of Geography and Environmental Development, Ben Gurion University of the Negev Beer Sheva, Israel

\begin{abstract}
The grain size distributions of bed load collected during flows that range from the threshold of motion to near bankfull in Nahal Eshtemoa, a coarse-grained ephemeral stream of southern Israel, give an unequivocal quantification of the change from unequal to near-equal mobility of grains of all available sizes. This second threshold occurs at $\sim 4.5$ times the shear stress associated with initial motion $\left(4.5 \tau_{c}\right)$. The level determined in Eshtemoa is much higher than previously defined by laboratory flume studies. The difference probably reflects the tighter packing and the greater interlock of natural streambeds and carries implications for a number of issues, including the modeling of sediment transport, especially in the context of dryland reservoir sedimentation. The proportion of time that flow exceeds $4.5 \tau_{c}$ determines the size distribution of cumulative bed load. Using a flow duration/sediment transport approach, in which fractional transport rates by grain size class are predicted with Parker's [1979] bed load function, it can be shown that the size distribution of bed load coarsens as the flow duration curve of individual flash floods incorporates progressively higher flows of variable duration. The method has utility because simple flood parameters such as peak discharge are imperfect predictors of sediment flux, particularly in desert streams where the shape of the flood hydrograph varies considerably from event to event. It is also shown that over a longer period (annual or decadal) the caliber of cumulative bed load depends upon the spectrum of flows in incident floods. The 4-year hydrograph record in Eshtemoa provides a modelderived bed load size distribution just finer than the unarmored bed material. The Eshtemoa data set can also be used to show clearly that water discharge in this type of ephemeral stream is "effective" or "dominant" over a wide range of flow stage ranging from 0.4 to 1.1 times bankfull and that bankfull discharge is no more significant than a wide range of other states of flow in transporting bed load.
\end{abstract}

\section{Introduction}

It is generally recognized that greater strength of flow is required to entrain the coarser fractions of the material that make up a riverbed [Ferguson et al., 1989; Komar and Shih, 1992] and that complete mobilization of each size fraction occurs over a range of flow strength [Wilcock and McArdell, 1993, 1997]. At comparatively modest levels of flow, coarser fractions are transported at rates that are typically several orders of magnitude less than those of finer fractions. Consequently, the size distribution of the bed load is often reported as being finer than that of the surface bed material [e.g., Ashworth et al., 1992; Lisle, 1995; Wathen et al., 1995]. As flow strength increases, progressively larger clasts are entrained and

Copyright 2001 by the American Geophysical Union.

Paper number 2000WR900342.

0043-1397/01/2000WR900342\$09.00 the bed load grain size distribution should converge with that of the surface bed material [Wilcock, 1992].

The changing nature of the transport processes associated with the evolution of bed load grain size distributions has been most extensively and most successfully investigated in laboratory flumes. Here, it is possible to conduct experimental programmes that cover a range of conditions from incipient motion to full mobilization. For example, the flume experiments of Wilcock and McArdell [1993] involved a permutation consisting of 28 variously coupled observations of flow, sediment transport, and bed surface grain size distribution that were subjected to a seventeenfold range of bed shear stress and yielded a fivefold variation in transport rate. In the field the determination of bed load transport rates by grain size over a similar range of transport conditions is probably impossible. In part, this is because bed load transport in many gravel bed rivers is marginal or fairly small even at comparatively high levels of flow [Parker, 1979; Andrews, 1984]. This, together with 
the dangers and difficulties of undertaking fieldwork in highenergy environments, has limited most field data sets to shortterm observations that cover a narrow range of comparatively low shear stresses and commensurably low bed load discharges. Although such studies have resulted in important and invaluable insights into a number of bed load transport processes [e.g., Ashworth and Ferguson, 1989; Gomez, 1995], they provide only limited snapshots of the transport dynamics of the rivers under study. An extrapolation of the trends that are perceived in such data sets to higher flow intensities may be inviting [Komar and Shih, 1992], but the often erratic nature of river sediment transport urges caution if stepping beyond the bounds of the empirical data [Reid and Frostick, 1986]. Any attempt to extend the range of flow conditions incorporated in an analysis by compiling transport measurements from different sites or from different epochs at the same location is usually complicated by differences in the nature of the sediments of each river, such as clast shape or sorting, or by differences in the field and analytical methods that have been deployed in collecting data [Richards, 1990].

In attempting to assess the evolution of bed load grain size the data collected at Oak Creek [Milhous, 1973], Goodwin Creek [Kuhnle, 1992], and the Alt Dubhaig [Wathen et al., 1995] using permanently installed sediment samplers have been particularly valuable. Although such measurement programmes are difficult to establish and expensive to maintain, they allow sediment transport data to be collected over a wider range of hydraulic conditions than is usually possible by the manual deployment of portable samplers. However, even here, only the data set for Goodwin Creek documents the transition from marginal to unrestricted sediment transport as flow intensity increases.

The evolution of grain size distributions with flow strength inevitably has implications for the nature of the bed load sediment yield of a water catchment. The significance of this might be seen, for example, in the accumulation of the deltas in water supply reservoirs, where unforeseen reductions in impoundment capacity may have serious consequences, especially in the world's drylands [Reid et al., 1998a]. An understanding of the caliber of sediment entering a reservoir might provide a basis for allowing a suitable volume for sedimentation in design and preproject cost-benefit analyses. It might also reduce the need for the postproject maintenance, such as dredging and sluicing, that bedevils reservoir construction in drylands [e.g., Tolouie et al., 1993]. There are other areas of fluvial geomorphology where an understanding of bed load grain size evolution would be invaluable. For example, in situations where regulated low flows require periodic maintenance of riverbed character for ecological reasons, an assessment of the entrainment thresholds of progressively larger size fractions can be invaluable in determining levels of flow that will provide sufficient activation of the bed material [Kondolf and Wilcock, 1996]. Where riverbed aggradation or degradation would bring adverse consequences, e.g., in the vicinity of bridge piers and other structures, the stability of the bed sediment might be assessed if the relation between flow and the armor layer grain size distribution were understood [Habersack, 1998]. Indeed, understanding this relation might assist in classifying channels as capable of transporting bed load at either "capacity" or "subcapacity" rates, thus helping to predict river behavior in situations where transport data are unavailable [Reid et al., 1996].

In this paper, we analyze the bed load grain size distributions of Nahal Eshtemoa in an attempt to unravel further the com- plexities of grain-size-dependent bed load sediment transport. This is part of a wider investigation of sediment transport processes in dryland ephemeral streams [Laronne and Reid, 1993; Laronne et al., 1994; Reid and Laronne, 1995; Reid et al., 1996, 1998b]. The data have been collected using a permanently installed sediment transport monitoring station. They characterize the change from low to high rates of bed load transport that occurs with increasing flow intensity. The sensitivity of bed load grain size to changing flow strength is described first. The findings are then used to consider the implications of this for the size distribution of lumped bed load that is transported out of the catchment during individual storms of varying magnitude and over longer time intervals that incorporate a spectrum of flood magnitudes.

The fact that the data were derived under a wide range of hydraulic conditions using the same technique throughout and that they were collected at a single site gives a homogeneous set of information with which to demonstrate that increasing flow strength brings a shift from unequal to near-equal mobility of bed material grains of different sizes. The fact that the data are field-based removes those complications that are inherent in flume studies and which arise from an unknown degree of artificiality, such as the under looseness that inevitably accompanies the construction of an alluvial bed of coarse-grained material and the need to feed sediment.

\section{Nahal Eshtemoa Study Site}

Nahal Eshtemoa is a fifth-order stream that drains the southwestern flanks of the Hebron Hills $\sim 100 \mathrm{~km}$ south of Jerusalem. With a mean annual rainfall of only 220-350 mm the channels of this region do not maintain perennial flow but are subject instead to discrete flash floods [Reid et al., 1994]. Flood hydrographs are typically multipeaked, with rates of rise as high as $0.24 \mathrm{~m} / \mathrm{min}$. However, the channel bed is usually dry within 12 to 96 hours. An analysis of flow duration for the period 1991-1995 indicates that the channel of the Eshtemoa is hydrologically active for only $\sim 2 \%$ of the time, or $\sim 7 \mathrm{~d} / \mathrm{yr}$ [Reid et al., 1998b].

The study reach is straight, and the channel is $6 \mathrm{~m}$ wide with near-vertical banks of $1.2 \mathrm{~m}$ height. The mean bed slope is 0.0075 . The bed immediately upstream of the samplers is planar and consists of poorly sorted pebbles and granules with an interstitial mix of fines. Approximately $20 \%$ of the bed material is $<1 \mathrm{~mm}$. Size distributions truncated at $1 \mathrm{~mm}$ yield median surface $\left(D_{b}\right)$ and subsurface particle sizes of 17 and $18 \mathrm{~mm}$, respectively, indicating that the channel is not armored (Figure 1). The lack of a streambed armor is thought to reflect the sparsely vegetated gullied hillslopes of the upper catchment, which ensures that sediment is freely supplied to the river channel [Laronne et al., 1994]. This characteristic is shared with other channels where sediment is readily moved into the stream network from adjacent hillslopes [e.g., Lisle and Madej, 1992].

\section{Field Instrumentation and Data}

Comprehensive details of the instrumentation are given by Laronne et al. [1992] and Powell et al. [1999]. Briefly, bed load transport rates are obtained with five automatic Birkbeck-type recording bed slot samplers [Reid et al., 1980] installed across the width of the stream. Each sampler operates independently and continuously weighs the bed load that falls through a slot 

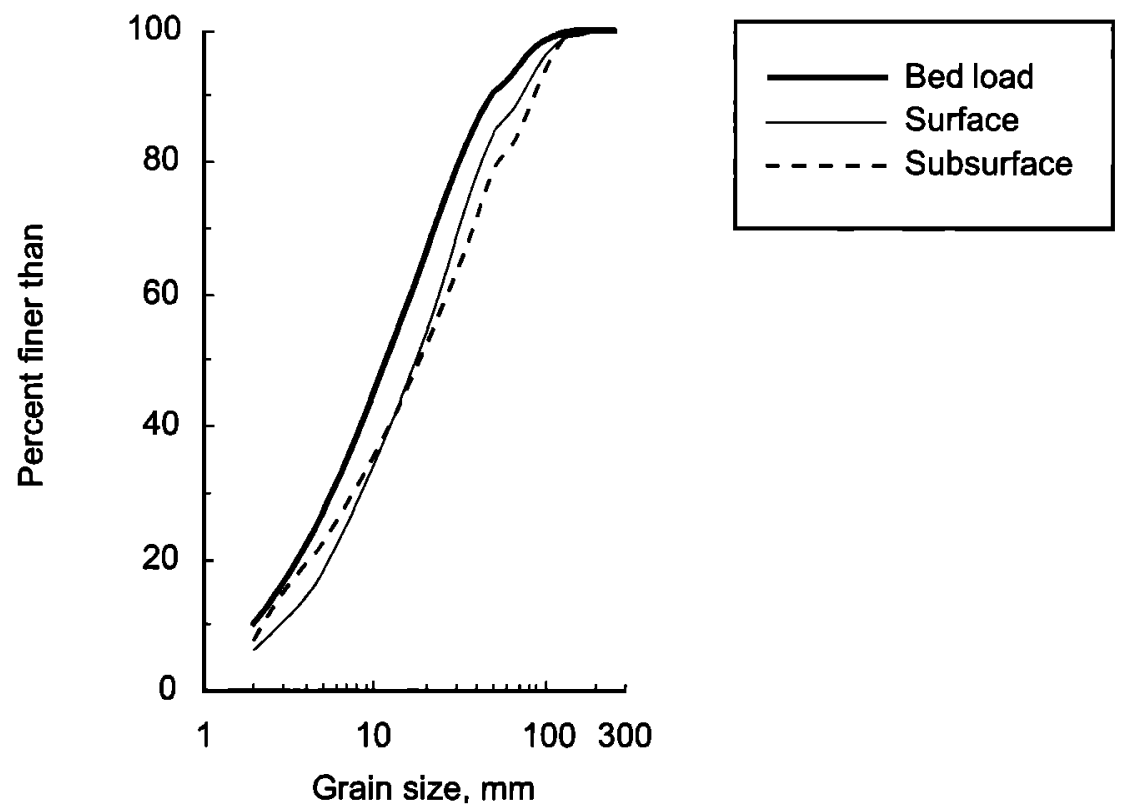

Figure 1. Average surface and subsurface bed material grain size distributions for the reach above the sediment transport monitoring station. Also shown is the predicted size distribution of the bed load transported out of the catchment over the 4-year study period. (Note that size distributions are truncated at $1 \mathrm{~mm}$.)

into an underlying container. A water stage pressure transmitter that is housed in a bankside stilling well measures the depth of flow at the sampling cross section. A second pressure transmitter located $70 \mathrm{~m}$ upstream of the samplers provides a second record of flow depth that is used to define the water surface slope in the approach reach. The varying measure of water surface slope $(S)$ has been used in conjunction with values of the hydraulic radius $(R)$ and a specific weight of water $(\gamma)$ that takes into account the high suspended sediment concentrations to derive estimates of channel-average shear stress $(\tau)$ using the du Boys' equation $(\tau=\gamma R S)$.

The du Boy's equation expresses the balance between the downslope component of the weight of water and the total force of bed resistance and is strictly limited to flows that are uniform and steady. Although most naturally occurring flows are nonuniform and unsteady, the equation can be reasonably applied if (1) the measurements of water surface slopes are made over a streamwise distance that is greater than that over which an open channel flow responds to a change in boundary conditions and (2) the time variation of the flow is sufficiently slow that it does not play an important role in the force balance [Paola and Mohrig, 1996]. Although our slope measurements approximate Paola and Mohrig's critical length scale for flow uniformity, the time variation of flow is sufficiently strong that we cannot rule out some error in our estimates of shear stress arising from the unsteadiness of the river's discharge regime.

Analysis of the bed load record and observations of the movement of painted pebble tracers suggests a threshold shear stress for incipient motion $\left(\tau_{c}\right)$ of $\sim 7 \mathrm{~N} \mathrm{~m}^{-2}$ [Reid et al., $1998 \mathrm{~b}]$. This is equivalent to a critical dimensionless shear stress of 0.03 for the $D_{b}$, a value increasingly used to describe incipient motion in gravel bed streams [Parker, 1979; Andrews, 1994]. Above this threshold, channel-average transport rates approximate the transporting capacity of the flow [Reid et al., 1998b; Powell et al., 1999]. Because transport capacity is high, the samplers fill rapidly and sampling is generally confined to the first few tens of minutes of each flood event. However, in judging the length of each record it should be remembered that a flash flood hydrograph can rise and fall within the hour and that the time of rise is typically $<20$ min so that a wide range of hydraulic conditions is being monitored on each occasion.

An analysis of the spatial pattern of bed load transport rate [Powell et al., 1999] indicates that transport rates at the channel center are about twice those recorded at the channel margins. This pattern reflects the variation in velocity and shear stress that would be generated by sidewall drag in a symmetrical trapezoidal cross section and is consistent with laboratory evidence of variations in shear stress [e.g., Knight et al., 1994].

After each event, bed load grain size distributions were obtained by sampling in $0.1 \mathrm{~m}$ layers the material that had accumulated in each sampler, ignoring the layer immediately below the slot. Because a Birkbeck sampler continuously records the accumulation of bed load, each of the bed load layers can be assigned to an interval for which transport rates and contemporary hydraulic conditions can be defined (Figure 2). This procedure depends upon the assumption that bed load accumulates evenly within the sampler. In fact, this is an approximation. Inspection of the shape of those deposits formed during the few events that did not fill the samplers indicates that bed load accumulates as a ridge, its apex lying directly beneath, and parallel to, the longitudinal slot in the sampler cover. The gradients on the sides of the ridge are variable but indicate dispersal of sediment as it settles within the sampler. This allows us to have confidence that within reason, each layer is representative of the material in transport during a defined interval for which we can specify hydraulic conditions. However, in addition to deriving information for each layer, the size distributions have been combined to provide a single curve for each sampler and each flood event, effectively yielding data for the bulk sample of material collected at each location and on each occasion.

Although material moving in suspension may have been carried into the samplers through the slot in each cover, we do not expect the amounts to be significant. Consequently, we can 

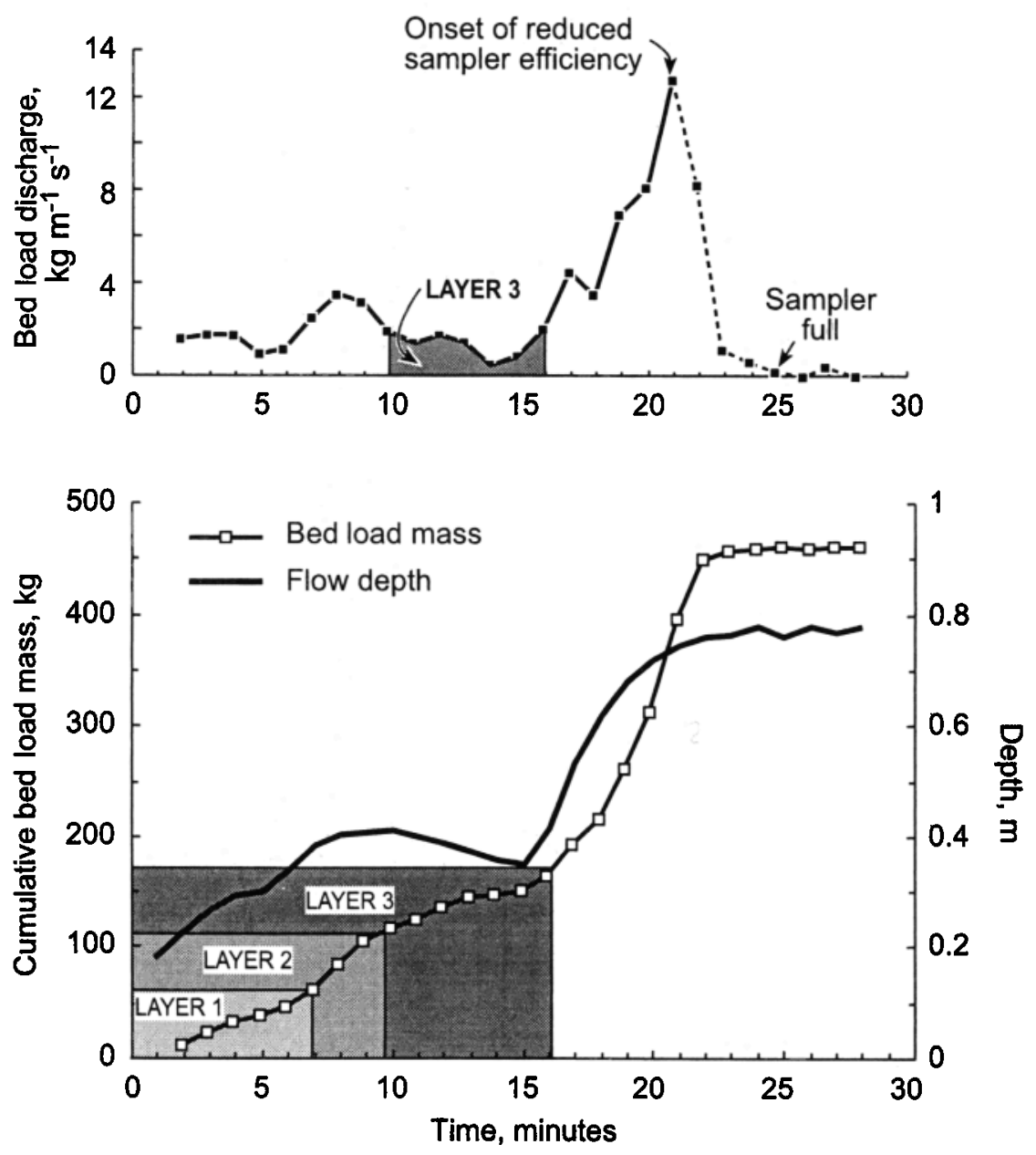

Figure 2. Temporal variation in rate of bed load accumulation and flux in the left center sampler for the event of November 5, 1994, illustrating the procedure for assigning a sampling interval to each of the bed load sample layers.

be confident that the material trapped by the samplers was moved as bed load, as is the case with slot samplers elsewhere, e.g., on the East Fork River [Leopold and Emmett, 1997; Habersack et al., 1998]. The slot width of each sampler was set at $110 \mathrm{~mm}$ in order to extend the sampling interval in the context of the very high bed load flux and the finite volume of each collecting chamber. Because the entrapped bed load occasionally incorporates a small fraction of grains as large as the slot width and because there may be uncertainty concerning sampling efficiency as grain size approaches slot width even with a longitudinal slot length of $450 \mathrm{~mm}$, we have used an upper truncation of $90 \mathrm{~mm}$ in presenting the results of our analysis of the grain size distributions. However, we can indicate that a more severe grain size truncation of $65 \mathrm{~mm}$ does not materially alter the patterns in the data and the conclusions that we draw.

In order to relate the size of transported clasts to the population available, samples of both the surface and subsurface bed material were derived from a number of sites at different locations within the sampler approach reach at various times during the 1993-1994 and 1994-1995 flood seasons. A limited number of bed material samples were taken on each occasion so that disturbance of the bed in the reach immediately upstream of the bed load sampling station was minimized. The highest number of samples taken on a single occasion came from 21 locations, but eight was more typical. Areal samples of the surface were obtained by spraying representative $1 \mathrm{~m}^{2}$ patches of the bed with paint and collecting all painted particles. A volumetric sample of the subsurface material was then taken to a depth of $0.15 \mathrm{~m}$ in each case. For comparison with the subsurface samples the size distributions of the surface samples have been converted to volumetric equivalents using the method of Kellerhals and Bray [1971] and a conversion exponent of -1 , as recommended by Diplas and Fripp [1992]. It should be noted that these samples represent the material in the channel "flat" that extends for $\sim 40-50 \mathrm{~m}$ upstream of the samplers and that consists of pebbles and granules with occasional cobbles. They do not represent the channel bars that punctuate the long profile at intervals. The first bar is $50 \mathrm{~m}$ upstream of the samplers. These bars incorporate large cobbles and boulders that often form the nucleus of clusters. Inspection of marked examples of these clusters revealed that they had not been moved during the flood events reported here.

\section{Evolution of Bed Load Size Distribution With Increasing Shear Stress}

\subsection{Bed Load Grain Size Distributions}

Figure 3 shows the size distribution of bed load sampled at different shear stresses during six bed-load-generating flash 


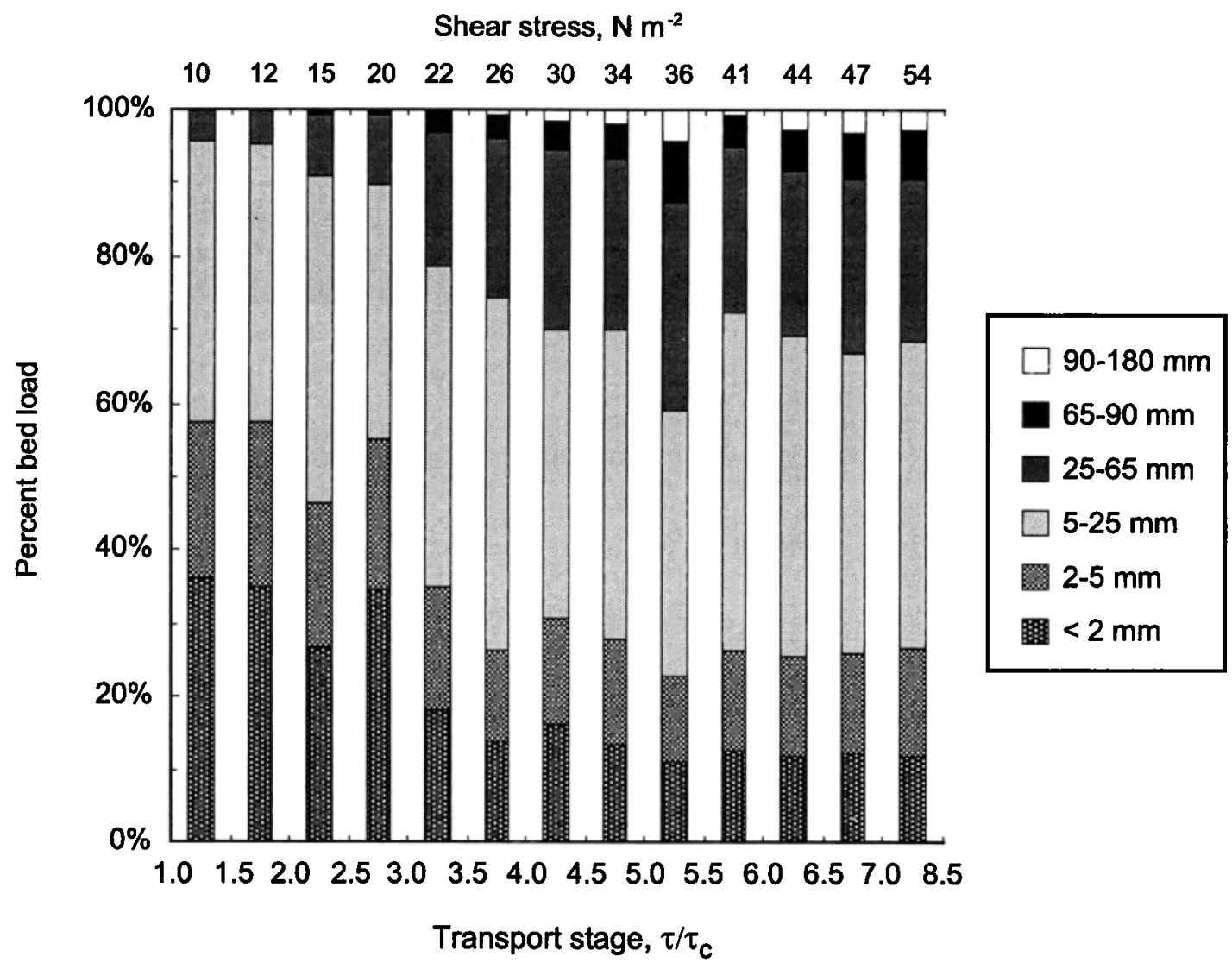

Figure 3. Mean bed load grain size distributions for $0.5 \tau_{c}$ shear stress bands (with the exception of the largest) arranged in order of increasing shear stress. (Note that there has been no size truncation.)

floods. Unlike subsequent analyses, all of the material is included and no upper size truncation has been applied. In order to clarify the emerging pattern the grain size distributions for all six events and all five samplers have been grouped into classes of contemporary shear stress based on 0.5 multiples of transport stage $\left(\tau / \tau_{c}\right)$, and an average size distribution has been derived for each class. (With only three samples obtained at $\tau / \tau_{c}>7.5$ these have been incorporated in an uppermost class with wider range.) Moreover, individual size classes have been combined into six groups, representing sand $(<2 \mathrm{~mm})$, granules $(2-5 \mathrm{~mm})$, fine pebbles $(5-25 \mathrm{~mm})$, coarse pebbles (25-65 mm), fine cobbles $(65-90 \mathrm{~mm})$, and medium cobbles (90-180 mm). At the lowest flows $\left(1<\tau / \tau_{c}<1.5\right), 57 \%$ of the load is sand- and granule-sized material. The remainder is dominated by fine pebbles ( $38 \%$ ), with only $4 \%$ comprising sediment coarser than $25 \mathrm{~mm}$. As shear stress increases, the grain size distribution coarsens as the proportion of bed load in the sand and granule classes falls and the proportions of coarse pebbles and fine cobbles rise. Interestingly, the proportion of fine pebbles does not change appreciably over the range of monitored flows. The transition to a pebble-dominated sediment load occurs over the range $3<\tau / \tau_{c}<4$. However, from the point at which shear stress is $\sim 4.5$ times the threshold value up to the limit of the data set $\left(\tau / \tau_{c}=8.5\right)$ the size distribution does not change appreciably and is characterized by $\sim 25 \%$ sand and granules, $\sim 67 \%$ pebbles, and $\sim 8 \%$ cobbles.

The shift toward coarser sizes with increasing flow strength can be assessed using the diameter of the bed load at different percentiles $\left(D_{x}\right)$ of the size distributions. Figures $4 \mathrm{a}-4 \mathrm{e}$ illustrate how the 16th, 50th, and 84th percentiles of the bed load grain size distributions vary with shear stress at each sampling location. Although there is a degree of scatter in each case, a consistent pattern of grain size variation emerges across the width of the channel. At each sampling location the grain size of each percentile increases steadily once the threshold of motion is exceeded but becomes more or less constant at high shear stresses. For example, median particle size $\left(D_{50}\right)$ increases from $\sim 3 \mathrm{~mm}$ at the lowest shear stresses to a value of $\sim 12 \mathrm{~mm}$ at shear stresses $>4.5 \tau_{c}\left(32 \mathrm{~N} \mathrm{~m}^{-2}\right)$. Comparable shifts are observed in the values of $D_{16}$ and $D_{84}$, which also attain near-constant values at $\tau \geq 4.5 \tau_{c}$.

The dependence of grain size on shear stress over the range $1<\tau / \tau_{c}<4$ was parameterized using ordinary least squares regression. Statistically significant trends are observed at four of the five sampling locations. (The nonsignificant result occurs at the left sampler, which is not unexpected given the limited number of bed load samples obtained at this location over this range of flows.) Although there are some statistically significant differences in the coefficients and exponents of the regression relations, they are not related systematically to either the sampling location (which would indicate differences in bed load grain size/shear stress response across the width of the stream) or bed load percentile (which would suggest changes in the shape of the grain size distribution curve with increasing flow strength). Thus it appears that despite chance variations in local sediment transport, a common relation between the sizes of material in transport and the flow is observed across the width of the stream, at least over these low to moderate shear stresses.

At higher shear stresses (from $\tau>4.5 \tau_{c}$ up to the highest 

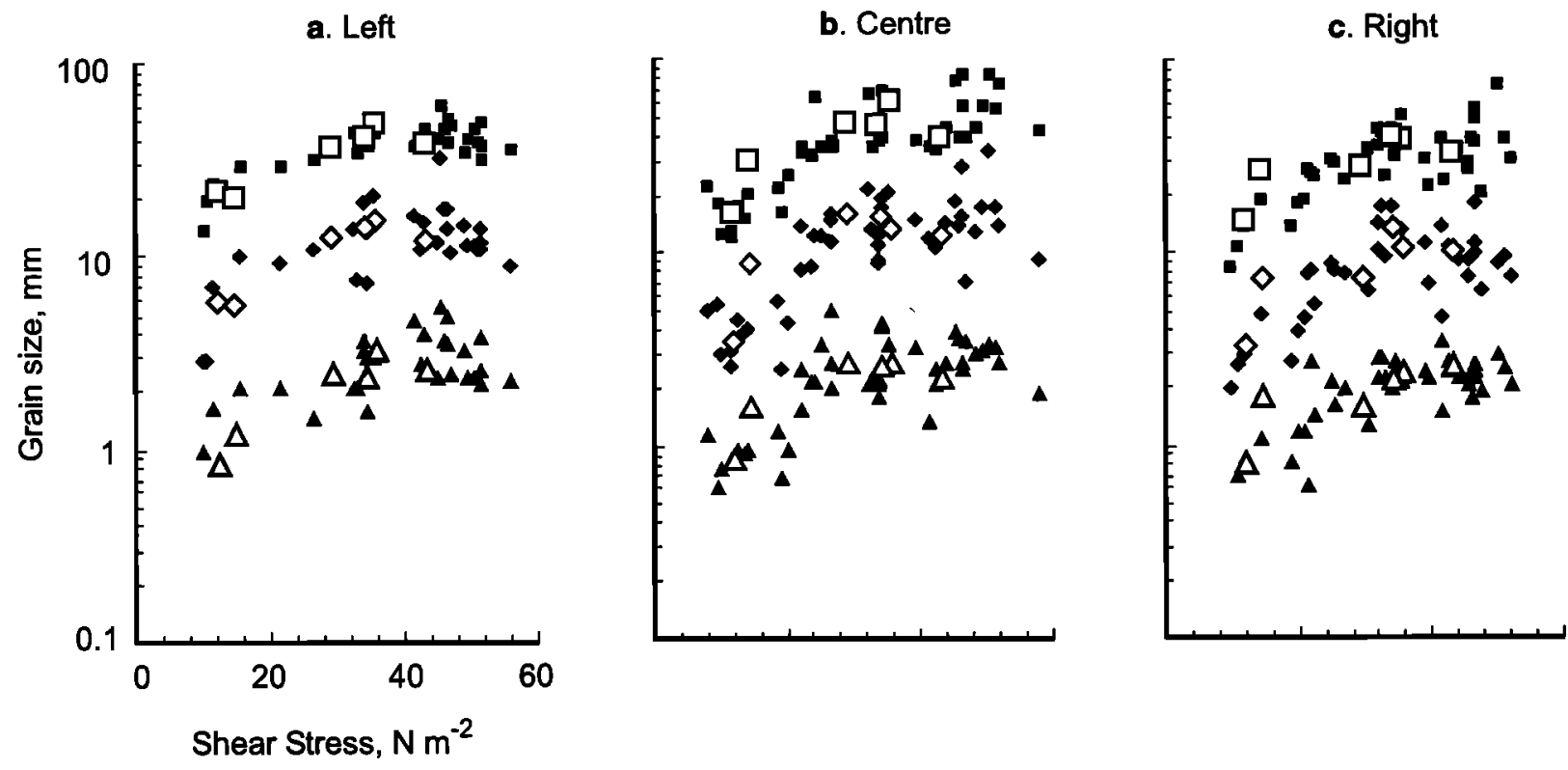

\section{d. Left centre}

e. Right centre

$\Delta \Delta \mathrm{D} 16$
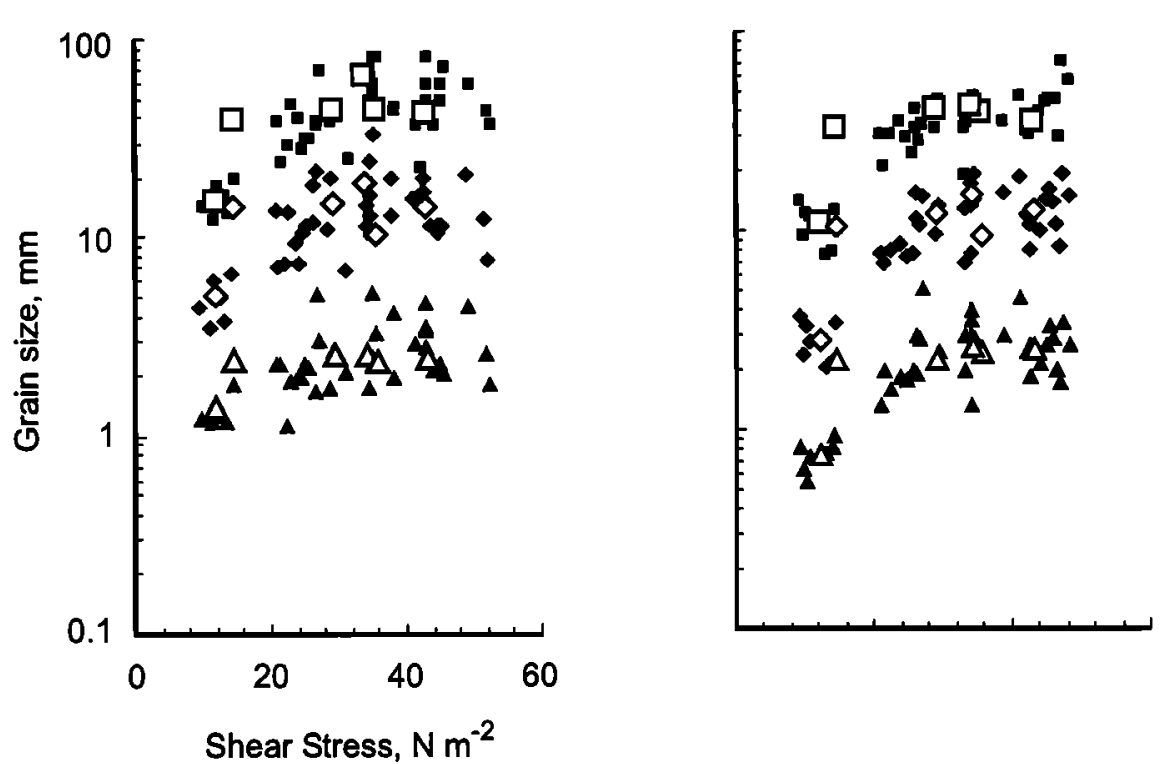

$\diamond \bullet$ D50

$\square \cdot \mathrm{D} 84$

Figure 4. Variation in grain size at the 16th, 50th, and 84th percentiles of the bed load size distribution with increasing shear stress at each of the five cross-stream sampler locations. Solid symbols represent percentile values of the size distributions obtained by layer sampling the sediment that filled each sampler; open symbols represent percentile grain sizes of the entire sediment that accumulated during a particular event.

level monitored), there is no statistically significant variation in grain size (Figure 4). The generally invariant nature of the size distribution at high shear stress can be confirmed by comparing the mean and the standard error of the mean of $D_{16}, D_{50}$, and $D_{84}$ at each sampling location over the range $4.5<\tau / \tau_{c}<$ 8.5. Low standard errors $(3-8 \%)$ confirm the transport of a near-constant grain size distribution, and the similarity of the mean values of each percentile provides further evidence for consistency in behavior across the width of the stream.

The pattern of grain size for specific percentiles versus shear stress that emerges from classification of each layer of the five samplers in all six flash floods is corroborated if the data are lumped, taking all of the sediment that had accumulated dur- ing an event and plotting the percentile grain size of this bulk sample against the average shear stress exerted over the period of sampling (open symbols in Figure 4). Even at this level of analysis, with very few plot points and mean values of shear stress representing a wide range of hydraulic conditions, the shift from flow dependence to flow independence with regard to the size distribution is clearly discernible.

\subsection{Comparison of Bed Load and Bed Material}

\section{Size Distributions}

The above analysis demonstrates that the bed load grain size coarsens as shear stress rises over the range $1<\tau / \tau_{c}<4.5$ but remains constant between $4.5<\tau / \tau_{c}<8.5$. However, 


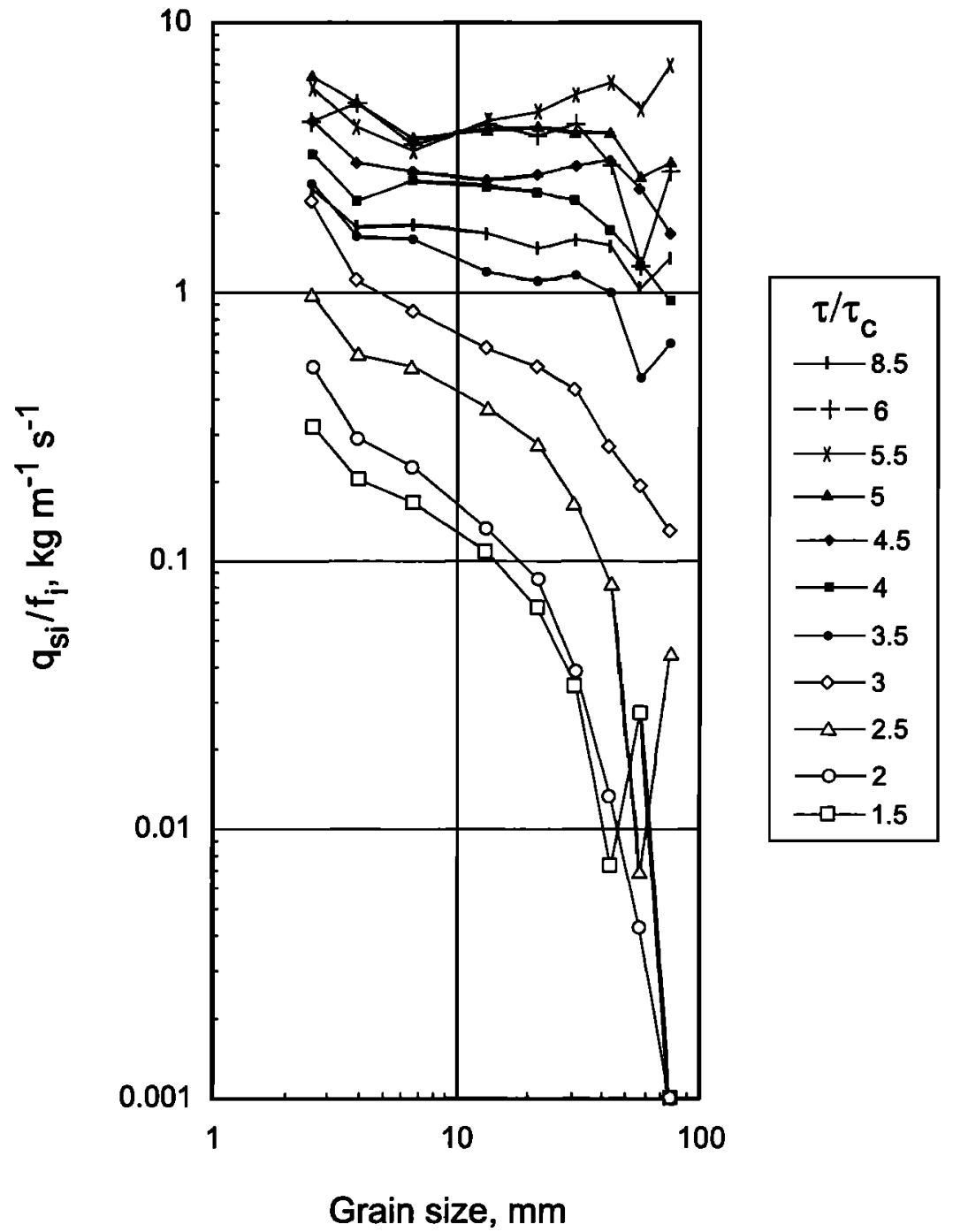

Figure 5. The ratio of mean fractional transport rate $\left(q_{s t}\right)$ with the frequency of occurrence in the bed $\left(f_{i}\right)$ of nine size fractions $(<90,<65,<50,<38,<25,<19,<9,<5$, and $3-2 \mathrm{~mm}$ ) as a function of the geometric mean grain size $\left(D_{i}\right)$ of each size fraction.

the full significance of these trends cannot be understood without reference to the size distribution of what may be considered as the sediment that is available for transport, i.e., that of the channel bed in the immediate approach reach of the samplers. A comparison of bed load and bed material grain size distributions can be undertaken if the transport rate of an individual fraction $\left(q_{s t}\right)$ is scaled by the proportion of the surface bed material in that size fraction $\left(f_{i}\right)$ and plotted against the geometric mean of the size fraction $\left(D_{t}\right)$. Since $q_{s i} / f_{i}$ is equivalent to $q_{s}\left(p_{t} / f_{t}\right)$, where $p_{t}$ is the proportion of the bed load in fraction $i$, a plot of $q_{s i} / f_{i}$ versus $D_{i}$ gives the transport grain size distribution in the form $p_{i} / f_{i}$ scaled by the total transport rate $q_{s}$ [Wilcock and Southard, 1988]. Different curves must be plotted for different values of $\tau$ since the overall transport rate will vary with the applied stress. The degree to which the curves deviate from horizontal indicates by how much the particle size distribution of the bed load departs from that of the bed material.

In Figure 5 we plot the arithmetic mean fractional transport rates for each of 11 ranges of shear stress corresponding to progressively higher classes of transport stage $\left(\tau / \tau_{c}\right)$, the up- per bounds of which are shown in the key. To ensure that any bed material which has been moved in suspension does not enter the comparison of bed load and bed material particle size distributions, both have been truncated to eliminate material finer than $2 \mathrm{~mm}$. This lower size limit is based on a suspension criterion, $\omega_{s}=u^{*}=(\tau / \rho)^{0.5}$, for the range of hydraulic conditions for which we have bed load transport data; in this formula, $\omega_{s}$ is the particle settling velocity estimated from the work of Dietrich [1982] with a Corey particle shape factor set at $0.7, u^{*}$ is the shear velocity, and $\rho$ is the density of the flow.

Figure 5 shows clearly that fine fractions are overrepresented and coarse fractions are underrepresented in the bed load at low to moderate shear stresses but that these discrepancies become less pronounced as shear stress increases. For example, the mobility of fine and coarse fractions differs by 2 orders of magnitude during flows that exert up to twice the threshold shear stress but differs by only a single order of magnitude during flows that exert 3 times the threshold. At shear stresses $\geq 4.5$ times the threshold the trends are essentially horizontal, with fractional transport rates varying by $<10 \%$ and with all values of $p_{\imath} / f_{i}$ insignificantly different from 
unity at the $95 \%$ level of probability. At these comparatively high intensities of flow, there is close similarity between the grain size distributions of the bed load and the bed material that is in the immediate approach reach of the samplers. The shift in the bed load size distribution confirms the now widely held view that bed load transport is strongly size selective when shear stress only just exceeds the threshold of the size fractions concerned and that a condition of equal mobility is approached as levels of excess shear stress become high [Ashworth and Ferguson, 1989; Wilcock and Southard, 1988; Kuhnle, 1992; Wilcock and McArdell, 1993; Laronne et al., 1994].

However, it should be noted that the Nahal Eshtemoa data set indicates that a near-equivalence between bed load and bed material grain size distributions is only reached when shear stress exceeds 4.5 times the threshold value. This is more than twice that suggested by flume studies [Wilcock, 1992], a value which is increasingly quoted as significant for gravel bed stream behavior [e.g., Thorne, 1992].

\section{Flow Magnitude, Flow Duration, and the Caliber of Bed Load Sediment Yield}

\subsection{Modeling Procedure}

Analysis of the Eshtemoa bed load size distributions indicates that bed load is fine grained at low flow but coarsens as flow rises during a flood event, converging with the grain size distribution of the bed at $\tau / \tau_{c} \approx 4.5$. As a function of this variable degree of clast size selection, the size distribution of the total bed load transported during an individual event should vary systematically with the magnitude of the event and the duration of the flow at various transport stages. In the same way, the size distribution of the sediment load evacuated from the catchment over a flood season or over a period of years should reflect the aggregate effect of the spectrum of competent flows.

In order to provide some insight into these matters the size distribution of the bed load transported during three contrasting flow events and during the 4-year study period was modeled using the flow duration/sediment transport method of Andrews and Nankervis [1995]. The procedure uses a relation between dimensionless shear stress and water stage in concert with a bed load transport function to calculate the quantity of bed material in each particle size fraction which is transported during increments of flow depth over a period of record. The bed load function chosen here is Parker's [1979] approximation of Einstein's [1950] bed load function. When applied to different size fractions in a mixed bed, the function is given by $\phi_{t} / f_{i}=11.2\left(\tau_{t}^{*}-\tau_{c t}^{*}\right)^{4.5} / \tau_{1}^{* 3}$ [Ferguson et al., 1989]. Here, $\phi_{t}$ is Einstein's dimensionless fractional transport rate, and $\tau_{i}^{*}$ and $\tau_{c i}^{*}$ are the dimensionless shear stresses and dimensionless critical shear stresses, respectively. Values of $\tau_{1}^{*}$ were derived from $\tau_{t}^{*}=\tau /\left(\gamma_{s}-\gamma\right) D_{t}$, in which $\gamma_{s}$ is the specific weight of the sediment, and estimates of $\tau_{c}^{*}$, were obtained using the reference transport method of Parker et al. [1982], as modified by Ashworth and Ferguson [1989].

Before we present the results of the flow duration/sediment transport analyses we must first consider the ability of Parker's [1979] equation to model the fractional transport rates and the size distribution of bed load in Nahal Eshtemoa. Such considerations are important given the uncertainty surrounding the general application of predictive bed load formulae [Carson and Griffiths, 1987; Gomez and Church, 1989]. In Figure 6a the observed transport rates for three representative size fractions are rated against the parameterized bed load function. It shows

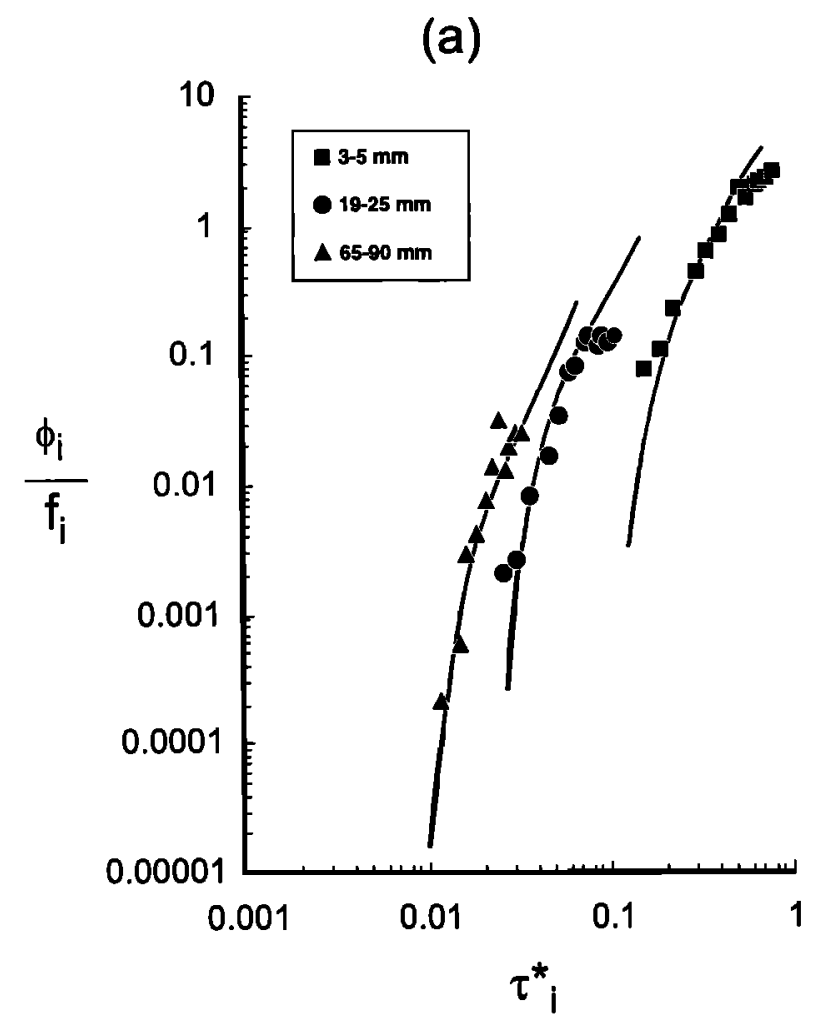

(b)

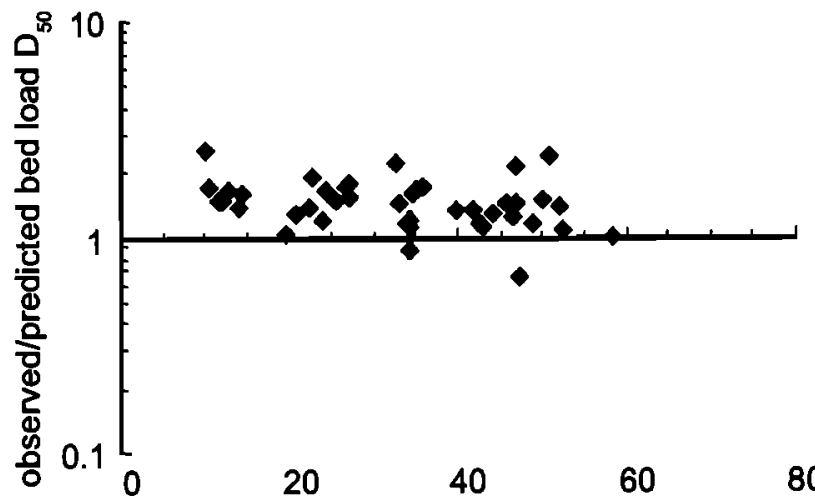

Shear stress, $\mathrm{N} \mathrm{m}^{-2}$

Figure 6. (a) Plot of observed and predicted dimensionless fractional transport rates as a function of dimensionless bed shear stress for selected size fractions. (b) Ratio of observed and predicted median bed load grain size at the center sampler as a function of shear stress. In Figures $6 \mathrm{a}$ and $6 \mathrm{~b}$, predicted values derive from the use of Parker's [1979] bed load equation.

that the model performs reasonably well. Predicted transport rates follow observed rates quite closely. For example, the median ratios of calculated to observed $(\mathrm{C} / \mathrm{O})$ fractional transport rates for the $3-5,19-25$, and $65-90 \mathrm{~mm}$ size fractions that are depicted are $1.2,0.7$, and 0.7 , respectively. Overall, the median $\mathrm{C} / \mathrm{O}$ ratio for the nine size fractions contained within 
(a)

\section{Very low-magnitude event 4-Jan-94}

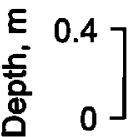

\section{Low-magnitude event} 11-Jan-93

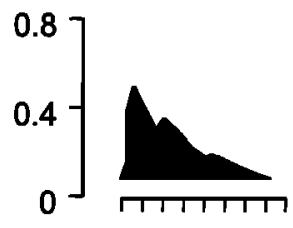

\section{Medium- magnitude event} 23-Nov-94

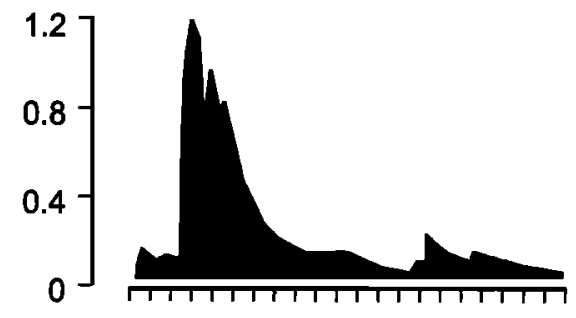

(b)

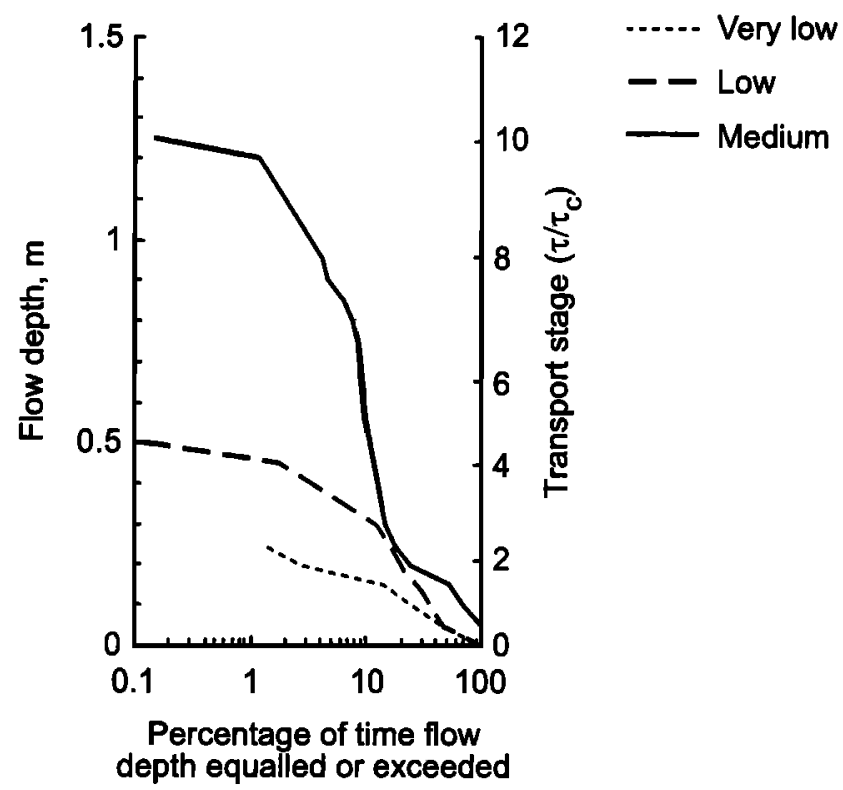

(c)

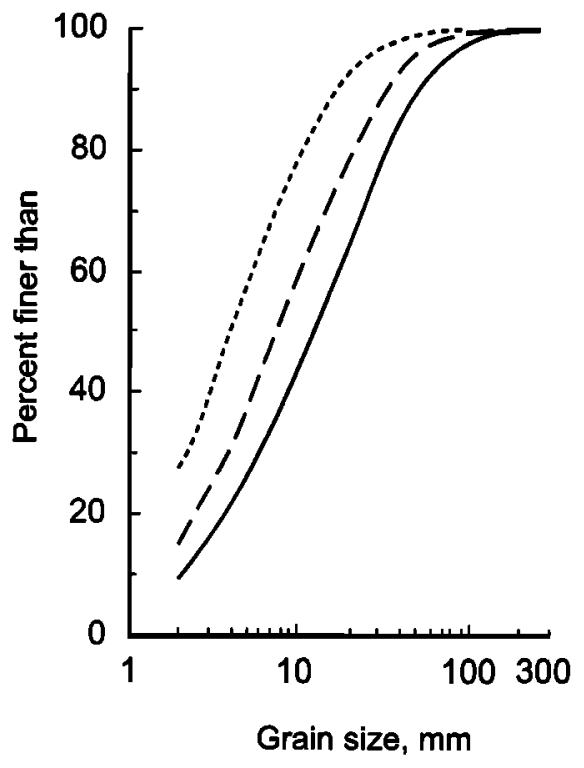

Figure 7. (a) Hydrographs, (b) flow duration curves, and (c) predicted bed load size distributions for three contrasting flow events. Ticks along the time axis of the hydrographs represent intervals of 2 hours.

the range $2.6<D_{i}<76 \mathrm{~mm}$ is 0.91 , with more than half the predicted values lying in a region $<3$ times the observed values and with $>90 \%$ lying within 5 times the observed values.

Given the similarity between observed and predicted fractional transport rates, it is not surprising that the bed load function also models the caliber of the sediment load reasonably well. Figure $6 \mathrm{~b}$ compares the median grain size of the observed and predicted sediment loads at different shear stresses. Although the predicted sediment load is slightly finer than that which is observed at all but the highest shear stresses, it is apparent that the predicted values are broadly comparable with observed values. The similarity of the observed and predicted fractional transport rates (Figure 6a) and of the respective grain size distributions (Figure 6b) suggests that application of the flow duration/sediment transport method utilizing the bed load function of Parker [1979] may produce reasonable estimates of both the bed load yield and its size distribution in Nahal Eshtemoa.

\subsection{Size Distribution of Bed Load Carried by Individual Floods}

The floods of January 4, 1994, January 11, 1993, and November 23,1994, are used to illustrate the sensitivity of the bed load grain size distributions to increasing flood magnitude (Figure 7). These three floods were chosen as representatives of very low-, low-, and medium-magnitude events, respectively.

The event of January 4, 1994, was one of the lowest flow events to generate bed load during the study period. Peak transport stage did not exceed the threshold value $\left(\tau / \tau_{c} \approx\right.$ 4.5) required to mobilize quasi-equally all the grain sizes in the approach reach, and size-selective transport processes prevailed for the duration of competent flow. As a result, the coarsest size fraction entrained by the event was finer than the coarsest fraction of the bed material and, with a $D_{50}$ of only 3 $\mathrm{mm}$, the predicted size distribution of the bed load was considerably finer than that of the bed material. In marked contrast, the event of November 23, 1994, was one of four bankfull events that occurred during the study period. A transport stage of 10 was attained at peak flow, and competent flows exceeded the threshold of near-equal mobility $\left(4.5 \tau_{c}\right)$ for $\sim 20 \%$ of the time. The result was the mobilization of all available size fractions and a much coarser predicted grain size distribution $\left(D_{50}=11 \mathrm{~mm}\right)$.

The event of January 11, 1993, was of low magnitude. It had 


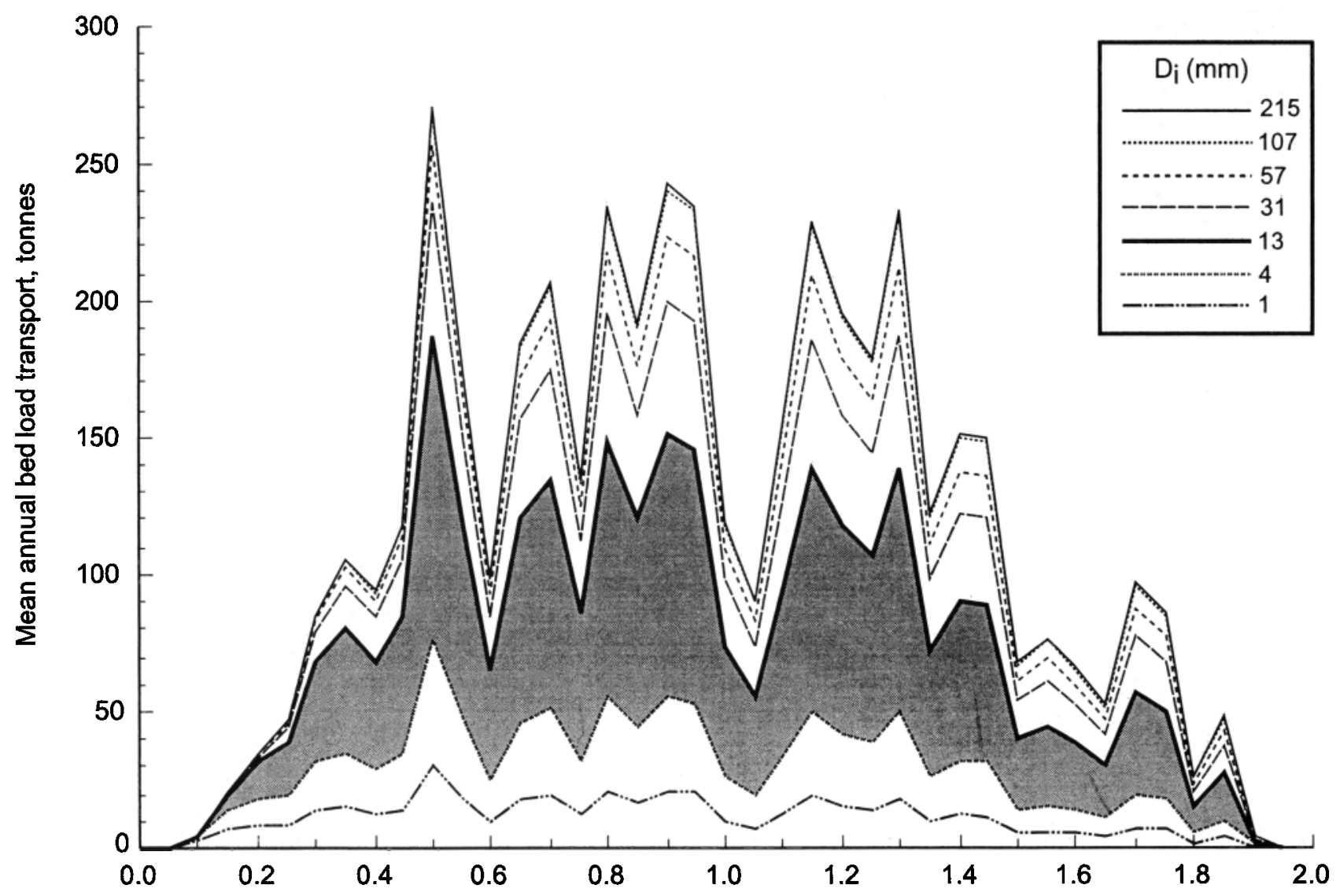

Flow depth, $m$

Figure 8. Predicted annual efflux of bed load from the Eshtemoa water catchment $\left(119 \mathrm{~km}^{2}\right)$ as a function of flow stage. Bankfull is at $1.2 \mathrm{~m}$.

a peak transport stage that was only half that attained during the event of November 23, and flows exceeded the threshold of equal mobility for only $10 \mathrm{~min}$. However, for $\sim 10 \%$ of its duration the flow had a transport stage of between three and four. These are transitional conditions under which increasingly coarse grains are being entrained. As a result, the predicted bed load had a size distribution that is intermediate between that generated by the medium- and very lowmagnitude events, with a $D_{50}$ of $6 \mathrm{~mm}$. Clearly, the caliber of bed material that is moved during a particular event will reflect not only the magnitude of the transporting flows but also their duration. The shape of the flood hydrograph therefore plays an important part in determining the size distribution of the cumulative bed load. This analysis serves to highlight the difficulty of using simple parameters of flood flow, such as peak discharge, as predictors of bed load caliber, particularly in dryland streams where the shape of the flood hydrograph may vary considerably from event to event [Reid et al., 1998b].

\subsection{Size Distribution of Longer-Term Bed Load Yield}

The significance of this last point is well illustrated with reference to longer-term estimates of the size distribution of bed load transported out of a water catchment. Using the flow duration/sediment transport method described in section 5.1 and a flow duration curve derived from the 4-year study period, Figure 8 shows the accumulative quantity of bed material in each size fraction that is transported at $0.05 \mathrm{~m}$ increments of flow depth during the course of a year. The area between adjacent curves is the mean annual quantity of sediment transport for each size fraction. For example, the shaded area represents the mean annual sediment yield of pebbles whose size is $4-13 \mathrm{~mm}$. The mean annual quantity of sediment transported in all size fractions is therefore the total area below the top curve. Integration gives a bed load sediment yield of $38.9 \mathrm{t}$ $\mathrm{km}^{-2} \mathrm{yr}^{-1}$. Were we to vary the hiding function used to parameterize the bed load equation by $\pm 10 \%$, the change in outcome would be negligible with a range in yield between 38.6 and $39.1 \mathrm{t} \mathrm{km}^{-2} \mathrm{yr}^{-1}$. It is of interest that these yields computed using the flow duration/sediment transport method are corroborated by a previously published estimate of $39 \mathrm{t} \mathrm{km}^{-2}$ $\mathrm{yr}^{-1}$, which was derived from a sediment rating-curve method based on the empirical total bed load flux data [Powell et al., 1996]. However, as expected, varying the hiding function by $\pm 10 \%$ has an effect upon the predicted cumulative annual bed load size distribution, though this varies across the size spectrum. So, for example, $D_{16}$ shifts from 2.7 to $3.2 \mathrm{~mm} ; D_{50}$ shifts from 10.7 to $13 \mathrm{~mm}$; and $D_{84}$ shifts from 35 to $42 \mathrm{~mm}$.

The peaks and troughs of Figure 8 reflect differences in fractional flow duration at each increment of flow depth. They are interesting in themselves and may, perhaps, be characteristic of ephemeral streams, where the flood hydrograph is typically spiky and multipeaked [Reid et al., 1998b]. However, it 
should be borne in mind that the flow record used here covers only four flood seasons. As the record extends, the pattern might be expected to become less spiky as the number of floods, each with its peculiar hydrograph, smoothes the flow duration curve. However, it is interesting to speculate that the pattern for ephemeral streams would remain more complex than that of perennial systems, regardless of the length of the flow record, because of differences in the nature of rainfallrunoff between drylands and regions that have greater rainfall.

Of more interest to this paper is the grain size distribution of the sediment load. Figure 1 shows that the mean size distribution of the Nahal Eshtemoa bed load, estimated using the flow duration/sediment transport method, is only slightly finer than that of the bed material. So in this stream the size distribution of bed load generated over four flood seasons is almost the same as that of the bed material, even though flows under which bed load and bed material grain size similarity is achieved are only experienced for $27 \%$ of the time the channel is transporting bed load (equivalent to $11 \%$ of the time the channel is hydrologically active). Even though size-selective entrainment processes produce bed load size distributions that are finer than the size distribution of the bed material for the majority of the time that flow exceeds $\tau_{c}$, the rate of transport at flows $\geq 4.5 \tau_{c}$ almost serves to compensate, rendering the lumped bed load only slightly finer than the bed material.

\section{Conclusion}

The data set obtained from Nahal Eshtemoa provides an almost unique opportunity to assess the evolution of bed load transport processes in the field. Because the samplers are fully automatic, they facilitate sampling as transport stage increases to levels as high as $8.5 \tau_{c}$, covering flow conditions that range from incipient motion to the mobilization of all grain sizes that are represented in the bed surface immediately upstream of the monitoring station. The outcome is an identification of a second major threshold at $\sim 4.5 \tau_{c}$, below which entrainment is size selective and above which a condition approaching equal mobility prevails. The level of this threshold is about twice that previously suggested by flume studies which use sediment mixtures with comparable sorting coefficients [Wilcock, 1992; Wilcock and McArdell, 1993]. This difference is not inconsiderable. It might reflect the fact that a natural water-lain sediment with its interstitial fines will almost certainly exhibit a degree of interlock and adhesion that is impossible to replicate under laboratory conditions. It is of interest here that when Kuhnle's [1992, Figure 7.9] plot of $q_{s i} / f_{t}$ versus $D_{t}$ for Goodwin Creek is interpreted in terms of $\tau / \tau_{c}$, it can be suggested that equal mobility (i.e., horizontality of the curves) is reached somewhere between 3.9 and $5 \tau_{c}$, given that fractional transport rates at $3.9 \tau_{c}$ vary by half an order of magnitude whereas this discrepancy is virtually absent in the next curve in Kuhnle's [1992] Figure 7.9, i.e., at $5 \tau_{c}$.

The difference is significant for predicting the flux and caliber of bed load because flow duration decreases rapidly with increasing water stage in most low-order streams and rivers. A threshold of $2 \tau_{c}$ would give a much longer interval for nearequal mobility of all grain sizes than would a threshold of $4.5 \tau_{c}$. For the 4-year study period in Nahal Eshtemoa, for example, adoption of the higher threshold would decrease the period of flow that lies within the near-equal mobility transport domain by $50 \%$.

The use of a flow duration/sediment transport method to assess both the total and size-fractional bed load yields of individual floods and the extension of this method to provide estimates of the seasonal efflux of bed load is encouraged by the simple relation between bed load and hydraulics in this ephemeral channel [Reid et al., 1998b]. It is possible to fit a bed load function such as that of Parker [1979] with some confidence and to use this in conjunction with a flow duration curve to arrive at credible estimates of yield. However, the high degree of scatter in the bed load/shear stress relation that is typical of many perennial streams of similar size [Reid and Laronne, 1995] makes a similar analysis for these somewhat less prospective.

The application of the flow duration/sediment transport method provides a further indication of the difficulties of attempting to link sediment transport and channel crosssectional form in concepts such as "effective" and "dominant" discharge [Graf, 1988; Knighton, 1998]. Taking the peaks of mean annual bed load transport shown in Figure 8, it can be seen that Nahal Eshtemoa is "efficient" in transporting sediment over a wide range of water stage ranging from $\sim 0.4$ to $\sim 1.1$ times bankfull. No single water stage is dominant. Indeed, it might be argued that bankfull stage $(1.2 \mathrm{~m})$ is not particularly significant, and the Eshtemoa data confirm Pickup and Warner's [1976] rather speculative but nonetheless perceptive assertion that subbankfull water stages are more important and channel formative. It may be that the wide range of flow depths over which the Eshtemoa is efficient demonstrates a particular characteristic of ephemeral channels, given the poor armor layer development that typifies these systems [Laronne et al., 1994]. However, it reinforces the suggestion that caution is required in trying to define either short- or long-term river behavior with simple parameters of flow. It certainly illustrates that inbank flows are just as significant as bankfull flow in moving bed material and thereby maintaining channel geometry, at least in ephemeral streams.

Acknowledgments. This research was funded by the Natural Environment Research Council of the UK, the Israel Hydrological Service, and Ben Gurion University of the Negev. We extend our thanks to the numerous students of Ben Gurion University of the Negev who have assisted in the field and, in particular, Yitshak Yitshak. Comments by the referees (Roger Kuhnle, Gary Parker, and Peter Wilcock) and the editor (Tom Lisle) were valuable in helping us improve the final version of the paper.

\section{References}

Andrews, E. D., Bed material entrainment and hydraulic geometry of gravel-bed rivers in Colorado, Geol. Soc. Am. Bull., 95, 371-378, 1984.

Andrews, E. D., Marginal bed load transport in a gravel-bed stream, Sagehen Creek, California, Water Resour. Res., 30, 2241-2250, 1994.

Andrews, E. D., and J. M. Nankervis, Effective discharges and the design of channel maintenance flows for gravel-bed rivers, in Natural and Anthropogenic Influences in Fluvial Geomorphology: The Wolman Volume, Geophys. Monogr. Ser., vol. 89, edited by J. E. Costa et al., pp. 151-164, AGU, Washington, D. C., 1995.

Ashworth, P. J., and R. I. Ferguson, Size-selective entrainment of bed load in gravel-bed streams, Water Resour. Res., 25, 627-634, 1989.

Ashworth, P. J., R. I. Ferguson, P. E. Ashmore, C. Paola, D. M. Powell, and K. L. Prestegaard, Measurements in a braided river chute and lobe, 2, Sorting of bed load during entrainment, transport, and deposition, Water Resour. Res., 28, 1887-1896, 1992.

Carson, M. A., and A. G. Griffiths, Bedload transport in gravel channels, N. Z. J. Hydrol., 26, 1-151, 1987.

Dietrich, W. E., Settling velocities of natural particles, Water Resour. Res., 18, 1615-1626, 1982. 
Diplas, P., and J. B. Fripp, Properties of various sediment sampling procedures, J. Hydraul. Eng., 118, 955-970, 1992.

Einstein, H. A., The bed load function for sediment transportation in open channel flows, Tech. Bull. U.S. Dep. Agric., 1026, 1950.

Ferguson, R. I., K. Prestegaard, and P. J. Ashworth, Influence of sand on hydraulics and gravel transport in a braided, gravel-bed river, Water Resour. Res., 25, 635-643, 1989.

Gomez, B., Bedload transport and changing grain size distributions, in Changing River Channels, edited by A. Gurnell and G. Petts, pp. 177-199, John Wiley, New York, 1995.

Gomez, B., and M. Church, An assessment of bed load sediment transport formulae for gravel-bed rivers, Water Resour. Res., 25, 1161-1186, 1989.

Graf, W. L., Fluvial Processes in Dryland Rivers, Springer-Verlag, New York, 1988.

Habersack, H. M., Numerical sediment transport models-Theoretical and practical aspects, LAHS Publ., 249, 299-308, 1998.

Habersack, H. M., H. P. Nachtnebel, and J. B. Laronne, Hydraulic efficiency of a slot sampler: Flow velocity measurements in Drau River, Austria, in Gravel-Bed Rivers in the Environment, edited by P. C. Klingeman et al., pp. 749-754, Water Resour. Publ., Highlands Ranch, Colo., 1998.

Kellerhals, R., and D. I. Bray, Sampling procedures for coarse fluvial sediments, J. Hydraul. Div. Am. Soc. Civ. Eng., 98, 1165-1180, 1971.

Knight, D. W., K. W. H. Yuen, and A. A. I. Alhamid, Boundary shear stress distributions in open channel flow, in Physical Mechanisms of Mixing and Transport in the Environment, edited by $\mathrm{K}$. Beven, $\mathrm{P}$. Chatwin, and J. Millbank, pp. 51-87, John Wiley, New York, 1994.

Knighton, D., Fluvial Forms and Processes, Edward Arnold, London, 1998.

Komar, P. D., and S.-M. Shih, Equal mobility versus changing bedload grain sizes in gravel-bed streams, in Dynamics of Gravel-Bed Rivers, edited by P. Billi et al., pp. 73-93, John Wiley, New York, 1992.

Kondolf, G. M., and P. R. Wilcock, The flushing flow problem: Defining and evaluating objectives, Water Resour. Res., 32, 2589-2599, 1996.

Kuhnle, R. A., Fractional transport rates of bedload on Goodwin Creek, in Dynamics of Gravel-Bed Rivers, edited by P. Billi et al., pp. 141-155, John Wiley, New York, 1992.

Laronne, J. B., and I. Reid, Very high rates of bed load sediment transport in ephemeral desert rivers, Nature, 366, 148-150, 1993.

Laronne, J. B., I. Reid, Y. Yitshak, and L. E. Frostick, Recording bedload discharge in a semiarid channel, Nahal Yatir, Israel, in Erosion and Sediment Transport Monitoring Programmes in River Basins, edited by J. Bogen, D. E. Walling, and T. J. Day, LAHS Publ., 210, 79-86, 1992.

Laronne, J. B., I. Reid, Y. Yitshak, and L. E. Frostick, The nonlayering of gravel stream-beds under ephemeral flood regimes, $J$. Hydrol., 159, 353-363, 1994.

Leopold, L. B., and W. W. Emmett, Bedload and river hydraulicsInferences from the East Fork River, Wyoming, U.S. Geol. Surv. Prof. Pap., 1583, 1997.

Lisle, T., Particle size variations between bed load and bed material in natural gravel-bed channels, Water Resour. Res., 31, 1107-1118, 1995.

Lisle, T., and M. Madej, Spatial variation in armouring in a channel with high sediment supply, in Dynamics of Gravel-Bed Rivers, edited by P. Billi et al., pp. 277-296, John Wiley, New York, 1992.

Milhous, R. T., Sediment transport in a gravel-bottomed stream, Ph.D. dissertation, Oreg. State Univ., Corvallis, 1973.

Paola, C., and D. Mohrig, Palaeohydraulics revisited: Palaeoslope estimation in coarse-grained braided rivers, Basin Res., 8, 243-254, 1996.

Parker, G., Hydraulic geometry of active gravel rivers, J. Hydraul. Div. Am. Soc. Civ. Eng., 105, 1185-1201, 1979.

Parker, G., P. C. Klingeman, and D. C. McLean, Bedload and size distribution in paved, gravel-bed streams, J. Hydraul. Div. Am. Soc. Civ. Eng., 108, 544-571, 1982.
Pickup, G., and R. F. Warner, Effects of hydrologic regime on magnitude and frequency of dominant discharge, J. Hydrol., 29, 51-75, 1976.

Powell, D. M., I. Reid, J. B. Laronne, and L. E. Frostick, Bedload as a component of sediment yield from a semiarid watershed of the northern Negev, in Erosion and Sediment Yield: Global and Regional Perspectives, edited by D. E. Walling and B. W. Webb, LAHS Publ. 236, 389-398, 1996.

Powell, D. M., I. Reid, and J. B. Laronne, Hydraulic interpretation of cross-stream variation in bedload transport rate in two straight alluvial channels, J. Hydraul. Eng., 125, 1243-1252, 1999.

Reid, I., and L. E. Frostick, Dynamics of bedload transport in Turkey Brook, a coarse-grained alluvial channel, Earth Surf. Processes Landforms, 11, 143-155, 1986.

Reid, I., and J. B. Laronne, Bed load sediment transport in an ephemeral stream and a comparison with seasonal and perennial counterparts, Water Resour. Res., 31, 773-781, 1995.

Reid, I., L. E. Frostick, and J. T. Layman, The continuous measurement of bedload discharge, J. Hydraul. Res., 18, 243-249, 1980.

Reid, I., D. M. Powell, J. B. Laronne, and C. Garcia, Flash floods in desert rivers: Studying the unexpected, Eos Trans. $A G U, 75(39), 452$, 1994.

Reid, I., D. M. Powell, and J. B. Laronne, Prediction of bed-load transport by desert flash floods, J. Hydraul. Eng., 122, 170-173, 1996.

Reid, I., J. B. Laronne, and D. M. Powell, Flood flows, sediment fluxes and reservoir sedimentation in upland desert rivers, in Hydrology in a Changing Environment, edited by $\mathrm{H}$. Wheater and $\mathrm{C}$. Kirby, pp. 377-386, John Wiley, New York, 1998a.

Reid, I., J. B. Laronne, and D. M. Powell, Flashflood and bedload dynamics of desert gravel-bed streams, Hydrol. Processes, 12, 543$557,1998 \mathrm{~b}$.

Richards, K. S., Fluvial geomorphology: Initial motion of bed material in gravel-bed rivers, Prog. Phys. Geogr., 14, 395-415, 1990.

Thorne, C., Discussion "Equal mobility versus changing bedload grain sizes in gravel-bed streams" by P. D. Komar and S.-M. Shih, in Dynamics of Gravel-Bed Rivers, edited by P. Billi et al., pp. 98-100, John Wiley, New York, 1992.

Tolouie, E., J. R. West, and J. Billam, Sedimentation and desiltation in the Sefid-Rud reservoir, Iran, in Geomorphology and Sedimentology of Lakes and Reservoirs, edited by J. McManus and R. W. Duck, pp. 125-138, John Wiley, New York, 1993.

Wathen, S. J., R. I. Ferguson, T. B. Hoey, and A. Werritty, Unequal mobility of gravel and sand in weakly bimodal river sediments, Water Resour. Res., 31, 2087-2096, 1995.

Wilcock, P. R., Experimental investigation of the effect of mixture properties on transport dynamics, in Dynamics of Gravel-Bed Rivers, edited by P. Billi et al., pp. 109-130, John Wiley, New York, 1992.

Wilcock, P. R., and B. W. McArdell, Surface-based fractional transport rates: Mobilization thresholds and partial transport of a sand-gravel sediment, Water Resour. Res., 29, 1297-1312, 1993.

Wilcock, P. R., and B. W. McArdell, Partial transport of a sand/gravel sediment, Water Resour. Res., 33, 235-245, 1997.

Wilcock, P. R., and J. B. Southard, Experimental study of incipient motion in mixed-size sediment, Water Resour. Res., 24, 1137-1151, 1988.

J. B. Laronne, Department of Geography and Environmental Development, Ben Gurion University of the Negev, Beer Sheva 84105 , Israel. (john@bgumail.bgu.ac.il)

D. M. Powell, Department of Geography, Leicester University, Leicester LE1 7RH, England, UK. (dmp6@leicester.ac.uk)

I. Reid, Department of Geography, Loughborough University, Loughborough LE11 3TU, England, UK. (ian.reid@lboro.ac.uk)

(Received February 16, 2000; revised October 25, 2000; accepted October 25, 2000.) 